\title{
Primary inflammatory myofibroblastic tumor of the breast with rapid recurrence and metastasis: A case report
}

\author{
HUA-DONG ZHAO ${ }^{1 *}$, TAO WU ${ }^{1 *}$, JUN-QING WANG ${ }^{2 *}$, WEN-DONG ZHANG ${ }^{2 *}$, \\ XIAN-LI HE ${ }^{1}$, GUO-QIANG BAO ${ }^{1}$, YI LI $^{3}$, LI GONG $^{4}$ and QING WANG $^{1}$ \\ Departments of ${ }^{1}$ General Surgery, ${ }^{2}$ Rehabilitation, ${ }^{3}$ Gynaecology and Obstetrics and ${ }^{4}$ Pathology, \\ Tangdu Hospital, The Fourth Military Medical University, Xi'an 710038, P.R. China
}

Received March 31, 2012; Accepted August 13, 2012

DOI: $10.3892 / \mathrm{ol} .2012 .948$

\begin{abstract}
Primary inflammatory myofibroblastic tumor (IMT) of the breast is extremely rare; only 19 cases have been reported in the English literature. In the present study, we present a case of IMT in a 56-year-old female patient who was admitted to our hospital due to a mass found in her right breast. Mammogram and ultrasound revealed a well-circumscribed mass and surgery was performed. Histopathologically, the lesion was composed of spindle and inflammatory cells, including plasma cells and lymphocytes. Mitotic figures were not observed. Immunohistochemically, the tumor cells were positive for SM-actin, anaplastic lymphoma kinase (ALK) and vimentin and focal positive for desmin, but negative for NSE, S-100, CD117, CD34, NF, CD21, CD35 and CD68. Thus, we made a diagnosis of IMT and advised regular follow-up. However, the patient had local recurrence and metastasis to the left groin area 3, 7 and 10 months after the initial surgery. Notably, the histopathological characteristics of the recurrent and metastatic foci were similar to those of the initial specimen, but mitotic figures were clearly observed. Thus, we conclude that IMT shows occasionally malignant biological behavior although it is a neoplasm of intermediate biological potential that frequently recurs and rarely metastasizes. We advise that clinical physicians should regularly follow up patients after focal resection for IMT.
\end{abstract}

Correspondence to: Professor Li Gong, Department of Pathology, Tangdu Hospital, The Fourth Military Medical University, No. 1 Xinsi Road, Shaanxi, Xi'an 710038, P.R. China

E-mail: glzwd16@fmmu.edu.cn; gongli1976@126.com

Professor Qing Wang, Department of General Surgery, Tangdu Hospital, The Fourth Military Medical University, No. 1 Xinsi Road, Shaanxi, Xi'an 710038, P.R. China

E-mail: qingwangtd@hotmail.com

*Contributed equally

Key words: breast, inflammatory myofibroblastic tumor, recurrence, metastasis

\section{Introduction}

Inflammatory myofibroblastic tumors (IMTs) are composed of myofibroblastic cells accompanied by an inflammatory infiltrate of plasma cells, lymphocytes and eosinophils. IMT used to be considered as an inflammatory pseudotumor, xanthogranuloma, plasma-cell granuloma, plasma-cell pseudotumor or an inflammatory myofibroblastic tumor. IMT commonly occurs in the lung, mesentery, omentum and retroperitoneum, but it may also be observed in the extremities, head and neck region, liver, spleen, thyroid, gastrointestinal tract, genitourinary tract and other systems (1-11). The tumors usually follow a benign course, but recurrences have been documented in up to $25 \%$ of cases. Recurrence rates are related to body site, multifocality and completeness of resection (12-17). Rare malignant transformation has been reported $(18,19)$. It is rare for IMT to occur in the breast, and only 19 cases have been reported in the English literature (20-27). Moreover, recurrence or metastasis of IMT is exceedingly rare. Thus, we present a 56-year-old female patient with IMT of the breast which recurred and metastasized 3, 7 and 10 months after initial surgery. Our aim is to emphasize that IMT shows occasionally malignant biological behavior although it is a neoplasm of intermediate biological potential that frequently recurs and rarely metastasizes. Thus, clinical physicians should regularly follow up patients after focal resection for IMT.

\section{Case report}

A 56-year-old female was admitted to our hospital 5 days after finding a mass in the upper inner quadrant of her right breast. The patient had no adenopathy. Mammogram and ultrasound revealed a $4-\mathrm{cm}$ mass at the 1 o'clock position that was highly suspicious for malignancy. The rapid frozen section during surgery revealed that the mass was a tumor with potential malignancy. Thus, a resection of the mass without lymph nodules was performed after informing the family of the patient. Grossly, the specimen was a gray-yellow segment of fibroadipose tissue, measuring $6.8 \times 5.2 \times 3.5 \mathrm{~cm}$; it contained a well-circumscribed gray-white mass measuring $4 \times 4 \times 3 \mathrm{~cm}$. The cut surface was gray-white and the texture was soft. Microscopically, the tumor was mainly composed 

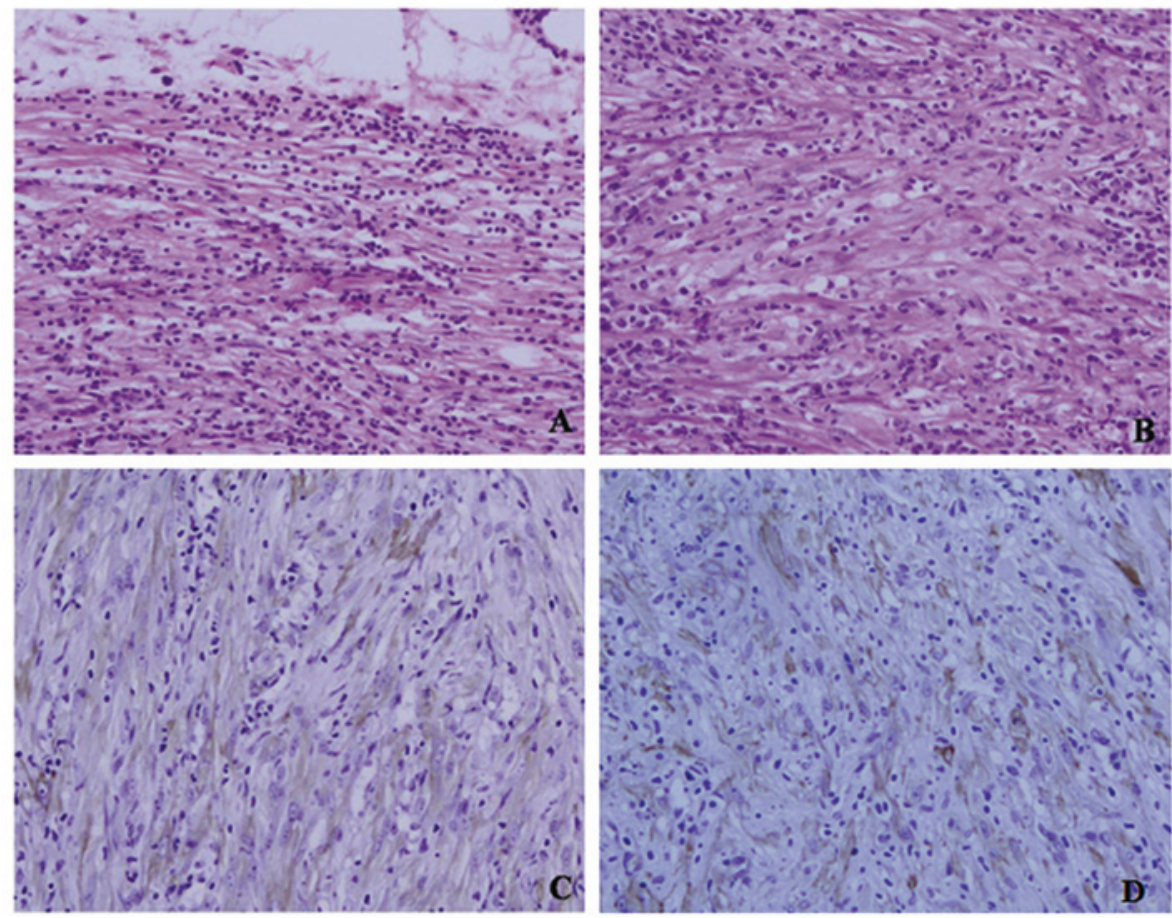

Figure 1. Tumor was mainly composed of spindle cells, forming swirling storiform-like patterns, and inflammatory cells, including plasma cells and lymphocytes . (A and B) The spindle cells were cytologically bland and most had wispy pink cytoplasm. No mitotic figures were found. (C and D) Immunohistochemically, the tumor cells were positive for ALK and SM-actin. ALK, anaplastic lymphoma kinase.
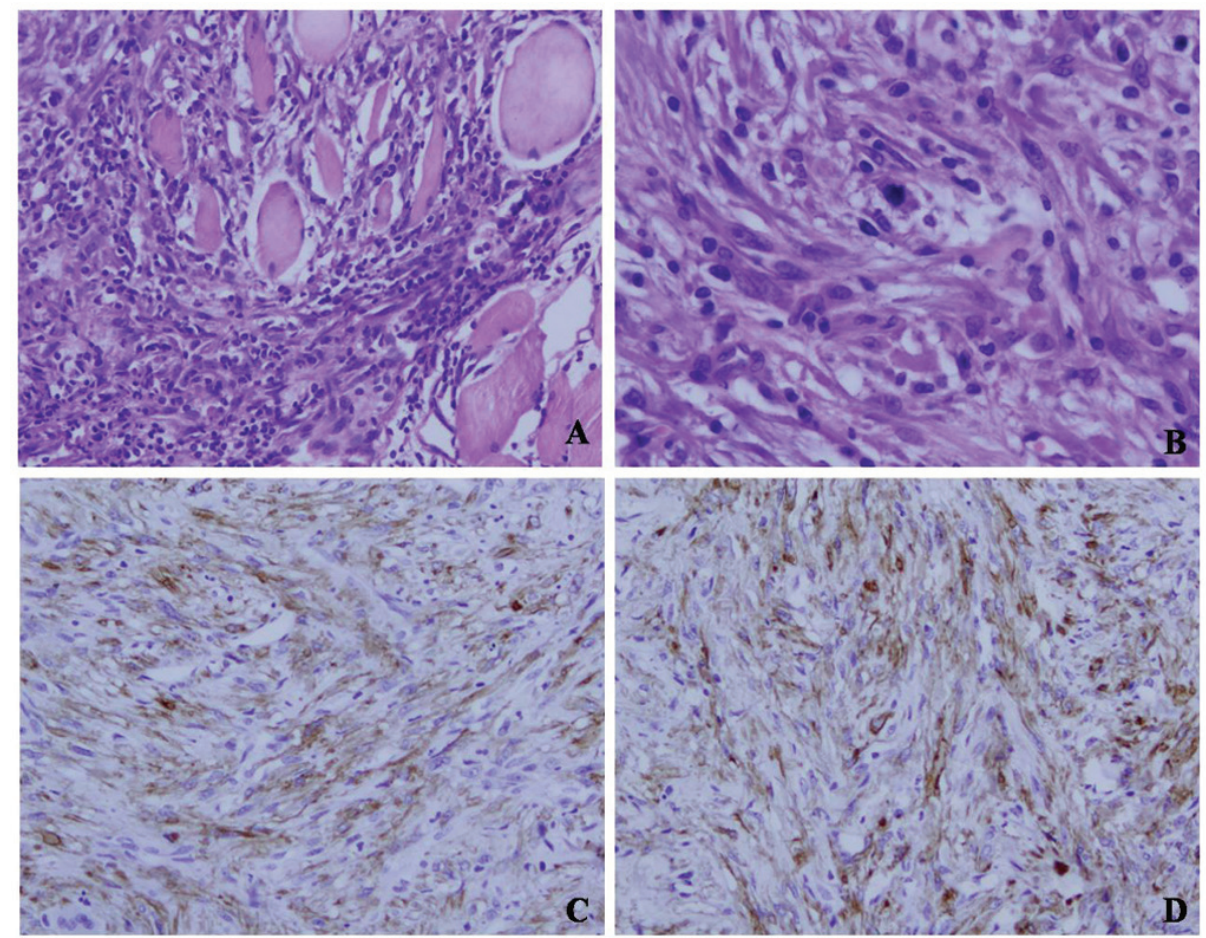

Figure 2. (A and B) The histopathological examination showed that the tumor cells had invaded into the surrounding striated muscle, and mitotic figures were found. (C and D) Immohistochemically, the tumor cells also expressed SM-actin and ALK. ALK, anaplastic lymphoma kinase.

of spindle cells, forming swirling storiform-like patterns, and inflammatory cells, including plasma cells and lymphocytes. The spindle cells were cytologically bland and most had wispy pink cytoplasm. No mitotic figures were found
(Fig. 1A and B). Immunohistochemically, the tumor cells were diffusely positive for SM-actin, anaplastic lymphoma kinase (ALK) and vimentin (Fig. 1C and D) and negative for CK, CD117, CD34, CD21, CD35, NSE, S-100 and NF. The 

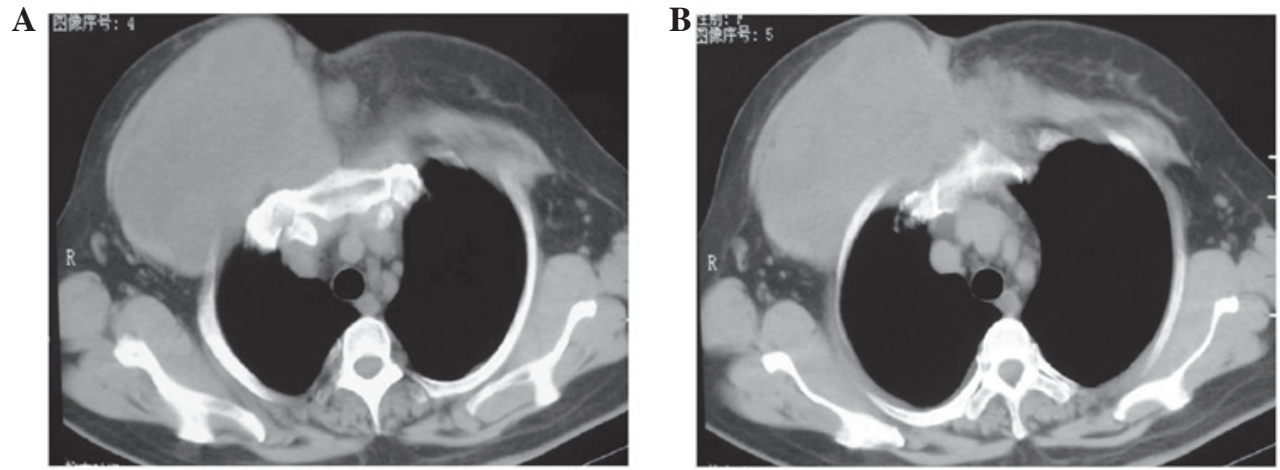

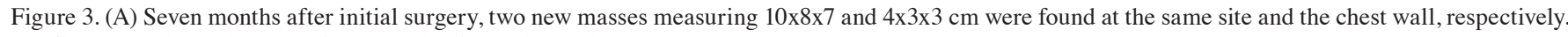
(B) CT revealed that the tumor involved the ribs and vessels.

margins of the resection were negative for tumor cells. Thus, we made a diagnosis of IMT and advised regular follow-up. However, three months later, a new mass measuring $3 \times 3 \times 3 \mathrm{~cm}$ was observed at the same site. Ultrasound revealed a mixed mass, and the site was considered to be a recurrent focus. A second excision was performed. The histopathological examination revealed that the tumor cells had invaded into the surrounding striated muscle. Moreover, mitotic figures were found (Fig. 2A and B). Immohistochemically, the tumor cells also expressed SM-actin and ALK (Fig. 2A and B). Thus, the diagnosis of malignant IMT was confirmed. Regular follow-up was again advised. Seven months after the initial surgery, two new masses measuring $10 \times 8 \times 7$ and $4 \times 3 \times 3 \mathrm{~cm}$ were found at the same site and the chest wall, respectively (Fig. 3A). CT scan revealed that the tumor involved the ribs and vessels (Fig. 3B). It was impossible to excise the mass. Thus, the patient received radiotherapy. However, the patient found a mass measuring $1.5 \times 1.0 \times 1.0 \mathrm{~cm}$ in her left groin area 10 months after the initial surgery. Needle biopsy revealed a tumor with spindle cells similar to the original tumor in the right breast. In addition, the tumor cells were positive for ALK, SM-actin and vimentin, but negative for desmin, CD117, CD34, NSE, S-100, CK, ALK, EMA, CD21 and CD35. Thus, we concluded that the site was a metastatic focus of IMT.

The study protocol was approved by the Medical Ethics Committee of the Fourth Military Medical University in Xi'an, China. Written informed consent was obtained from the patient.

\section{Discussion}

IMT was first described in the lungs in 1939 (28). It is an uncommon mesenchymal tumor, and it has been gradually recognized by pathologists and clinical physicians. IMT is composed of a spectrum of fibroblastic or myofibrotic proliferations with a varying infiltrate of inflammatory cells, including lymphocytes, plasma cells and histiocytes. Most IMTs occur in the lungs and airways of young patients. However, other organs, including mesentery, omentum, stomach, small intestine, large intestine, mediastinum, retroperitoneum, liver and bladder, have been documented (1-11). Among these extrapulmonary IMTs, $43 \%$ arise in the mesentery and omentum (29). Cases of IMT of the breast are scarce. To our knowledge, only 19 cases have been described in the English literature (20-27). Moreover, all the IMTs were unilateral and surgically excised. However, three showed recurrence following surgery, with two of the three patients having bilateral recurrence (30). With regard to our case, the tumor showed local recurrence 3 and 7 months after surgery. Notably, a metastatic focus was confirmed 10 months after the initialsurgical resection. IMT presents with recurrence, metastasis or malignant transformation in certain cases, although most tumors behave in a benign manner after surgical resection, and IMT is classified as an intermediate neoplasm in the World Health Organization histological typing. Patients diagnosed with IMT should be regularly followed up even if surgical resection is performed.

The pathogenesis of IMT is unknown. Some consider IMT to be an immunological response to an infectious or noninfectious insult $(31,32)$. Other researchers found that there was ectopic chromosomal rearrangements in the long arm of chromosome 2 and the short arm of chromosome 9, and confirmed that IMT was a monoclonal proliferation by genetic and molecular techniques (33-36). In addition, approximately half of IMTs harbor a clonal cytogenetic aberration that activates the ALK-receptor tyrosine kinase gene at 2p23 $(15,37)$. Thus, IMT should be considered as a true neoplasm, rather than inflammatory pseudotumor as at present. These aggressive features, such as local recurrence, metastasis and malignant transformation, suggested a neoplastic process. In our case, the tumor cells were positive for ALK besides SM-actin and vimentin and supported the diagnosis of IMT.

Similar to most soft-tissue sarcomas, IMTs are traditionally insensitive to chemotherapy and radiotherapy. In addition, nonsteroidal anti-inflammatory drugs (NSAIDs), steroids and cyclosporin-A have been used as treatment modalities, but surgical resection is considered to be the treatment of choice.

In conclusion, IMT shows occasionally malignant biological behavior although it is a neoplasm of intermediate biological potential that frequently recurs and rarely metastasizes. Thus, clinical physicians should regularly follow up patients after focal resection for IMT.

\section{Acknowledgements}

This study was supported by The National Natural Science Foundation of China (nos. 30800417 and 30801121). 


\section{References}

1. Kim EY, Lee IK, Lee YS, et al: Inflammatory myofibroblastic tumor in colon. J Korean Surg Soc 82: 45-49, 2012.

2. Pannain VL, Passos JV, Rocha Filho A, Villela-Nogueira C and Caroli-Bottino A: Agressive inflammatory myofibroblastic tumor of the liver with underlying schistosomiasis: a case report. World J Gastroenterol 16: 4233-4236, 2010.

3. Faraj W, Ajouz H, Mukherji D, Kealy G, Shamseddine A and Khalife M: Inflammatory pseudo-tumor of the liver: a rare pathological entity. World J Surg Oncol 9: 5, 2011.

4. Singh S, Chhabra S, Modi S, Marwah N, Rawal A and Arora B: Inflammatory pseudo-tumor of the spleen. Indian J Patho Microbiol 52: 564-565, 2009.

5. Bruyeer E and Ramboer K: Multiple inflammatory pseudotumors of the liver and spleen. JBR-BTR 93: 122-123, 2010.

6. Trimeche M, Ziadi S, Mestiri S, et al: Inflammatory myofibroblastic tumor of the thyroid in its sclerosing subtype: the first case report. Eur Arch Otorhinolaryngol 266: 763-766, 2009.

7. Choi AH, Bohn OL, Beddow TD and McHenry CR: Inflammatory myofibroblastic tumor of the small bowel mesentery: an unusual cause of abdominal pain and uveitis. J Gastrointest Surg 15: 584-588, 2011.

8. Hirschburger M, Enders J, Alzen G, Padberg W and Wagner HJ: An inflammatory myofibroblastic tumor of the stomach as a rare cause of gastric outlet obstruction in an 8-month-old infant. Klin Padiatr 222: 192-193, 2010.

9. Chow SC, Nahal A, Mayrand S and Ferri LE: Pulmonary inflammatory myofibroblastic tumor invading the gastroesophageal junction. Ann Thorac Surg 89: 1659-1661, 2010.

10. Chen Y, Tang Y, Li H, et al: Inflammatory myofibroblastic tumor of the esophagus. Ann Thorac Surg 89: 607-610, 2010.

11. Lecuona AT, Van Wyk AC, Smit SG, Zarrabi AD and Heyns CF: Inflammatory myofibroblastic tumor of the bladder in a 3-year-old boy. Urology 79: 215-218, 2012.

12. Dehner LP: Inflammatory myofibroblastic tumor: the continued definition of one type of so-called inflammatory pseudotumor. Am J Surg Pathol 28: 1652-1654, 2004.

13. Coffin CM and Fletcher JA: Inflammatory myofibroblastic tumour. In: Pathology and Genetics of Tumours of Soft Tissue and Bone. Fletcher CDM, Unni KK and Mertens F (eds). World Health Organization Classification of Tumours, IARC Press, Lyon, pp91-93, 2002.

14. Coffin CM, Watterson J,Priest JR and DehnerLP: Extrapulmonary inflammatory myofibroblastic tumor (inflammatory pseudotumor): A clinicopathologic and immunohistochemical study of 84 cases. Am J Surg Pathol 19: 859-872, 1995.

15. Coffin CM, Hornick JL and Fletcher CDM: Inflammatory myofibroblastic tumor: comparison of clinicopathologic, histologic, and immunohistochemical features including ALK expression in atypical and aggressive cases. Am J Surg Pathol 31: 509-520, 2007.

16. Makhlouf HR and Sobin LH: Inflammatory myofibroblastic tumors (inflammatory pseudotumors) of the gastrointestina tract: how closely are they related to inflammatory fibroid polyps? Hum Pathol 33: 307-315, 2002.

17. Montgomery EA, Shuster DD, Burkart AL, et al: Inflammatory myofibroblastic tumors of the urinary tract: a clinicopathologic study of 46 cases, including a malignant example inflammatory fibrosarcoma and a subset associated with high-grade urothelial carcinoma. Am J Surg Pathol 30: 1502-1512, 2006.

18. Ernst CW, Van Der Werff Ten Bosch J, Desprechins B, De Mey J and De Maeseneer M: Malignant transformation of an abdominal inflammatory myofibroblastic tumor with distant metastases in a child. JBR-BTR 94: 78-80, 2011.
19. Lu CH, Huang HY, Chen HK, et al: Huge pelvi-abdominal malignant inflammatory myofibroblastic tumor with rapid recurrence in a 14-year-old boy. World J Gastroenterol 16 : 2698-2701, 2010

20. Park SB, Kim HH, Shin HJ and Gong G: Inflammatory pseudotumor (myoblastic tumor) of the breast: a case report and review of the literature. J Clin Ultrasound 38: 52-55, 2010.

21. Kim SJ, Moon WK, Kim JH, Cho N and Chang CM: Inflammatory pseudotumor of the breast: a case report with imaging findings. Korean J Radiol 10: 515-518, 2009.

22. Hill PA: Inflammatory pseudotumor of the breast: a mimic of breast carcinoma. Breast J 16: 549-550, 2010.

23. Akbulut M, Gunhan-Bilgen I, Zekioglu O, Duygulu G, Oktay A and Ozdemir N: Fine needle aspiration cytology of inflammatory myofibroblastic tumour (inflammatory pseudotumour) of the breast: a case report and review of the literature. Cytopathology 18: 384-387, 2007.

24. Khanafshar E, Phillipson J, Schammel DP, Minobe L, Cymerman $\mathrm{J}$ and Weidner $\mathrm{N}$ : Inflammatory myofibroblastic tumor of the breast. Ann Diagn Pathol 9: 123-129, 2005.

25. Ilvan S, Celik V, Paksoy M, Cetinaslan I and Calay Z: Inflammatory myofibroblastic tumor (inflammatory pseudotumor) of the breast. APMIS 113: 66-69, 2005.

26. Zardawi IM, Clark D and Williamsz G: Inflammatory myofibroblastic tumor of the breast. A case report. Acta Cytol 47: 1077-1081, 2003

27. Sastre-Garau X, Couturier J, Derré J, Aurias A, Klijanienko J and Lagacé R: Inflammatory myofibroblastic tumour (inflammatory pseudotumour) of the breast. Clinicopathological and genetic analysis of a case with evidence for clonality. J Pathol 196: 97-102, 2002.

28. Brunn H. Two interesting benign lung tumors of contradictory histopathology: remarks on the necessity for. J Thorac Surg 9: 119-131, 1939.

29. Khoddami M, Sanae S and Nikkhoo B: Rectal and appendiceal inflammatory myofibroblastic tumors. Arch Iran Med 9: 277-281, 2006.

30. Vecchio GM, Amico P, Grasso G, Vasquez E, La Greca G and Magro G: Post-traumatic inflammatory pseudotumor of the breast with atypical morphological features: A potential diagnostic pitfall. Report of a case and a critical review of the literature. Pathol Res Pract 207: 322-326, 2011.

31. Coffin CM, Humphrey PA and Dehner LP: Extrapulmonary inflammatory myofibroblastic tumor: a clinical and pathological survey. Semin Diagn Pathol 15: 85-101, 1998.

32. Hojo H, Newton W, Hamoudi A, et al: Pseudosarcomatous myofibroblastic tumor or the urinary bladder in children: a study of 11 cases with review of the literature. Am J Surg Pathol 19: 1224-1236, 1995.

33. Griffin C, Hawkins A, Dvorak C, et al: Recurrent involvement of 2 p23 in inflammatory myofibroblastic tumors. Cancer Res 59: 2276-2280, 1999.

34. Su L, Atayde-Perez A, Sheldon S, et al: Inflammatory myofibroblastic tumor: cytogenetic evidence supporting clonal origin. Mod Pathol 11: 364-368, 1998.

35. Snyder C, Dell'Aquila M, Haghighi $\mathrm{P}$, et al: Clonal changes in inflammatory pseudotumor of the lung. A case report. Cancer 76: $1545-1549,1995$.

36. Sastre-Garau X, Couturier J, Derre J, et al: Inflammatory myofibroblastictumor (inflammatory pseudotumor) of the breast. Clinicopathological and genetic analysis of a case with evidence for clonality. J Pathol 216: 97-102, 2002.

37. Gleason BC and Hornick JL: Inflammatory myofibroblastic tumours: where are we now? J Clin Pathol 61: 428-437, 2008. 